(REVIEW ARTICLE)

\title{
Epidemiology and impact of SARs Corona Virus 2 in animals and human health with one health concept: A review
}

\author{
Edget Abayneh ${ }^{1,}{ }^{*}$ and Henok Goba ${ }^{2}$ \\ ${ }^{1}$ Arba Minch University, College of Agricultural science, Department of Animal Science \\ ${ }^{2}$ Arba Minch Zuria Woreda, Livestock and fishery resource office.
}

Publication history: Received on 11 October 2020; revised on 20 December 2020; accepted on 23 December 2020

Article DOI: https://doi.org/10.30574/wjarr.2020.8.3.0383

\begin{abstract}
Corona viruses infect many species of animals, including humans. Coronaviruses have been described for more than $50 y e a r s$ but up to 2003, only two coronaviruses were identified to infect humans. From 2002 to 2003, Severe Acute Respiratory Syndrome Coronavirus (SARS-CoV) affected more than 8000 people and caused about 800 deaths around the world. After a few years a novel coronavirus was recognized in September, 2012, later renamed Middle East Respiratory Syndrome Coronavirus (MERS-CoV). In December 2019, 2019 novel Coronavirus (nCoV), which is another public health problem, has emerged in the Huanan Seafood Market, where livestock animals are also traded, in Wuhan State of Hubei Province in China and has been the focus of global attention due to a pneumonia epidemic of unknown cause. The Corona viridae Study Group of ICTV named this novel Coronavirus as SARS-Cov-2. In March 2020 the World Health Organization declared the SARS-Cov-2 virus a global pandemic. The pandemic is ongoing and its study and further scientific works on it are still running and in conclusion a one health approached are required to combat this situation with an integrated effort of human, animal and environmental health.
\end{abstract}

Keywords: COVID-19; Pandemic; SARS-Cov-2; Veterinary; Public Health

\section{Introduction}

Coronaviruses infect many species of animals, including humans. Coronaviruses have been described for more than 50years; the isolation of the prototype murine coronavirus strain JHM, for example, was reported in 1949. The molecular mechanisms of replication as well as the pathogenesis of several coronaviruses have been actively studied since the 1970s. Some of the animal viruses, such as porcine transmissible gastroenteritis virus (TGEV), bovine coronavirus (BCoV), and avian infectious bronchitis viruses (IBV), are of veterinary importance and the murine coronavirus mouse hepatitis virus (MHV) is studied as a model for human disease. This family of viruses remained relatively obscure, probably because there were no severe human diseases that could definitely be attributed to coronaviruses; human coronaviruses caused only the common cold (1).

Up to 2003, only two coronaviruses were identified to infect humans. Human coronavirus-229E (HCoV-229E) and human coronavirusOC43 (HCoV-OC43) were recognized in the 1960s. From 2002 to 2003, Sevier Acute Respiratory Syndrome Coronavirus (SARS-CoV) affected more than 8000 people and caused about 800 deaths around the world (2). After 2003, the SARS epidemic, two additional human coronaviruses-NL63 (HCoV-NL63) in 2004 and human coronavirus HKU1 (HCoV-HKU1) in 2005 were discovered (3) (4).

However, in the spring of 2003, when it became clear that a new human coronavirus was responsible for severe acute respiratory syndrome (SARS), coronaviruses became much more recognized with the occurrence of the SARS epidemic,

\footnotetext{
${ }^{*}$ Corresponding author: Edget Abayneh

Arba Minch University, College of Agricultural science, Department of Animal Science.
} 
coronaviruses may now be considered "emerging pathogens"(5). A novel coronavirus was recognized in September, 2012, later renamed Middle East Respiratory Syndrome Coronavirus (MERS-CoV) in an individual who died with an acute respiratory distress syndrome in Saudi Arabia (6).

This novel coronavirus belong lineage $\mathrm{C}$ of the genus Beta coronavirus included virus isolates from bats and somewhat close to bat coronavirus-HKU4 (BtCoV-HKU4) and bat coronavirus-HKU5 (BtCoV-HKU5) (7).

In December 2019, 2019 novel Corona virus (nCoV), which is another public health problem, has emerged in the Huanan Seafood Market, where livestock animals are also traded, in Wuhan State of Hubei Province in China and has been the focus of global attention due to a pneumonia epidemic of unknown cause. At first, an unknown pneumonia case was detected on December 12, 2019, and possible influenza and other coronaviruses were ruled out by laboratory testing. Chinese authorities announced on January 7, 2020 that a new type of Corona virus (novel Corona virus, $\mathrm{nCoV}$ ) was isolated. This virus was named as Novel Coronavirus WHO on January 12 and COVID-19 on 11 February 2020. In March 2020 the World Health Organization declared the SARS-Cov-2 virus a global pandemic (8).

The present outbreak of a coronavirus-associated acute respiratory disease called coronavirus disease 19 (COVID-19) is the third documented spillover of an animal coronavirus to humans in only two decades that has resulted in a major epidemic. The Corona viridae Study Group (CSG) of the International Committee on Taxonomy of Viruses, which is responsible for developing the classification of viruses and taxon nomenclature of the family Corona viridae, has assessed the placement of the human pathogen, tentatively named 2019-nCoV, within the Corona viridae. Based on phylogeny, taxonomy and established practice, the CSG recognizes this virus as forming a sister clade to the prototype human and bat severe acute respiratory syndrome coronaviruses (SARS-CoVs) of the species Severe acute respiratory syndrome-related coronavirus, and designates it as SARS-CoV-2 (9). Therefore the main objective of this review is to show the corona virus SARS-CoV 2 epidemiology and its impact in both human and animal with respect to one health concept.

\section{Corona Virus Epidemiology}

\subsection{History and Taxonomy}

The name "coronavirus," coined in 1968, is derived from the "corona"-like or crown-like morphology observed for these viruses in the electron microscope. In 1975, the Corona viridae family was established by the International Committee on the Taxonomy of Viruses. At the 10th International Nido virus Symposium in Colorado Springs, Colo., in June 2005, it was proposed that the Corona viridae family be divided into two subfamilies, the coronaviruses and the toro viruses, the latter of which cause enteric diseases in cattle and possibly in humans (1). The Corona viridae family, along with the Arte viridae and Roni viridae families, form the Nido virales order and Arte viridae family includes swine and equine pathogens, and the Roni viridae family is composed of invertebrate viruses (10).

The first known corona virus, the avian infectious bronchitis virus, was isolated in 1937 and was the cause of devastating infections in chicken. The first human coronavirus was isolated from the nasal cavity and propagated on human ciliated embryonic trachea cells in vitro by Tyrrell and Bynoe in 1965. However, coronaviruses have been present in humans for at least 500-800 years, and all originated in bats (11). Corona viruses have long been recognized as important veterinary pathogens, causing respiratory and enteric diseases in mammals as well as in birds and of the known corona virus species, only six have been known to cause disease in humans: HCoV-229E, HCoV-OC43, HCoV-NL63, HCoV-HKU1, severe acute respiratory syndrome corona virus (SARS-CoV) and Middle East respiratory virus corona virus (MERS$\mathrm{CoV})(12)$.

\subsection{Naming of Corona Virus 2}

Upon a viral outbreak, it is important to rapidly establish whether the outbreak is caused by a new or a previously known virus as this helps decide which approaches and actions are most appropriate to detect the causative agent, control its transmission and limit potential consequences of the epidemic. The assessment of virus novelty also has implications for virus naming and, on a different timescale, helps to define research priorities in virology and public health (9).

Virus nomenclature is a formal system of names used to label viruses and taxa. The fact that there are names for nearly all viruses within a species is due to the historical perception of viruses as causative agents of specific diseases in specific hosts, and to the way we usually catalogue and classify a newly discovered virus, which increasingly includes viruses that have not been linked to any known disease in their respective hosts (9). 


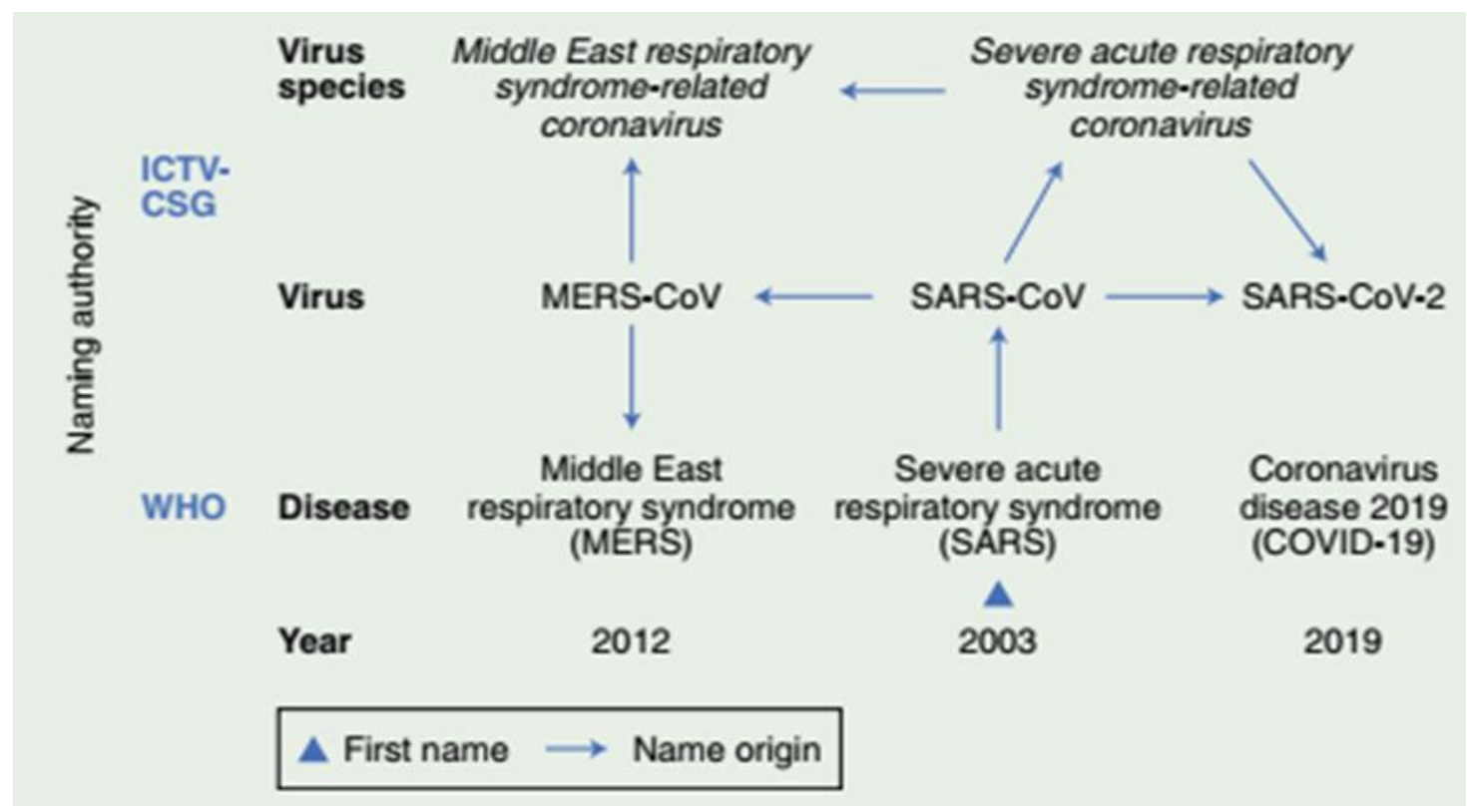

Figure 1 History of coronavirus naming during the three zoonotic outbreaks in relation to virus taxonomy and diseases caused by these viruses (9).

Researchers studying corona viruses have been confronted several times with the need to define whether a newly emerged virus causing a severe or even life-threatening disease in humans belongs to an existing or a new (yet-to-beestablished) species (13). This happened with SARS (14) and with Middle East respiratory syndrome (MERS) (15; 16) a few years later. Each time, the virus was placed in the taxonomy using information derived from a sequence based family classification (17).

The current classification of corona viruses recognizes 39 species in 27 subgenera, five genera and two subfamilies that belong to the family Corona viridae, suborder Cornido virineae, order Nido virales and realm Ribo viria. The family classification and taxonomy are developed by the Corona viridae Study Group (CSG), a working group of the ICTV. The CSG is responsible for assessing the place of new viruses through their relation to known viruses in established taxa, including placements relating to the species severe acute respiratory syndrome-related coronavirus (9).

Consistent with previous reports, SARS-CoV-2 clusters with SARS-CoVs in trees of the species severe acute respiratory syndrome related coronavirus and the genus Beta corona virus. Distance estimates between SARS-CoV-2 and the most closely related coronaviruses vary among different studies depending on the choice of measure (nucleotide or amino acid) and genome region (9).

\subsection{Corona Virus Diseases}

According to the report by (1) the viruses cause acute and chronic respiratory, enteric and central nervous system (CNS) diseases in many species of animals with serious impact on the public.

\subsection{Human Corona Virus}

Previous to the emergence of SARSCoV, there were two prototype human coronaviruses, OC43and 229E, both etiologic agents of the common cold. There had long been speculation about the association of human coronaviruses with more serious human diseases such as multiple sclerosis, hepatitis, or enteric disease in newborns (18). However, none of these early associations had been substantiated (1).

Currently, three types of coronaviruses have been isolated from humans: Human Corona viruses 229E, OC43, and SARS corona virus (SARS-CoV).There are 6 types of corona viruses previously known to infect humans. 229E and NL63 (of alpha corona viruses), OC43 (of beta corona viruses), HKU1, Middle East Respiratory Syndrome Coronavirus (MERSCoV), and Severe Acute Respiratory Syndrome Coronavirus (SARS-CoV) (19).

Recently, a novel corona virus was isolated from the lower respiratory tract of patients in Wuhan, who were suffering from pneumonia due to unknown causes the WHO called it 2019-nCoV while the International Committee on the 
Taxonomy of Viruses (ICTV) named it SARS-CoV-2. It was subsequently confirmed that the virus is capable of humanto-human transmission (source 20).

\subsection{Covid-19 Pandemic}

The COVID-19 epidemic expanded in early December of 2019 from Wuhan, China's 7th most populous city, throughout China and was then exported to a growing number of countries. The first confirmed case of COVID-19 outside China was diagnosed on 13th January 2020 in Bangkok (Thailand) (20). On the 2nd of March 2020, 67 territories outside mainland China had reported 8565 confirmed cases of COVID-19 with 132 deaths, as well as significant community transmission occurring in several countries worldwide, including Iran and Italy and it was declared a global pandemic by the WHO on the 11th of March 2020 (21). Currently the expansion of disease is ongoing and its global concern is still increasing.

\subsection{Clinical manifestation of Covid-19}

The most common symptoms of COVID-19 are fever, tiredness, dry cough and shortness of breath or difficulty breathing, some patients may have aches and pains in joints or muscles, repeated shaking with chills, nasal congestion, runny nose, sore throat, diarrhea, and loss of smell and taste in some cases according to available reports $(22 ; 23)$.

In severe cases, COVID-19 can be complicated by acute respiratory disease syndrome, sepsis and multiple organ failure and Most COVID-19 patients (85 percent) experience mild or uncomplicated illness, approximately 14 percent develop severe disease requiring hospitalization and 5 percent will require intensive care (22).

\section{Transmission}

As stated in FAO guidelines (24) even though this virus could have emerged from a spillover event after zoonotic exposure, the COVID-19 pandemic is due to human-to-human transmission where animals do not appear to play a role. The WHO reported that the virus can be transmitted (i) directly from person to person, when an infected person coughs, sneezes or speaks and produces droplets of saliva or discharge, that reach the nose, mouth or eyes of another person, or (ii) when a person touches contaminated objects or surfaces and then touches their eyes, nose or mouth. The virus can be detected and isolated in faeces and the role of faecal-oral transmission is yet to be determined. Aerosol transmission of the virus - in which fine particles or droplet nuclei are suspended in the air - may be possible in specific circumstances and settings (e.g. associated with aerosol generating procedures or treatment such as endotracheal intubation) (21).

\section{Diagnosis}

For patients with suspected infection, the following diagnosis techniques are utilized: performing real-time fluorescence (RT-PCR) to detect the positive nucleic acid of SARS-CoV-2 in sputum, throat swabs, and secretions of the lower respiratory tract samples and in patients with COVID-19, the white blood cell count can vary (25).

Leukopenia, leukocytosis, and lymphopenia have been reported, although lymphopenia appears most common Elevated lactate dehydrogenase and ferritin levels are common, and elevated aminotransferase levels have also been described. On admission, many patients with pneumonia have normal serum procalcitonin levels; however, in those requiring ICU care, they are more likely to be elevated. High D-dimer levels and more severe lymphopenia have been associated with mortality $(25 ; 26)$.

Imaging findings- Chest computed tomography (CT) in patients with COVID-19most commonly demonstrates groundglass opacification with or without consolidative abnormalities, consistent with viral pneumonia. Others study have suggested that chest CT abnormalities are more likely to be bilateral, have a peripheral distribution, and involve the lower lobes. Less common findings include pleural thickening, pleural effusion, and lymphadenopathy (27; $28 ; 29)$. Chest CT may be helpful in making the diagnosis, but no finding can completely rule in or rule out the possibility of COVID-19.

\section{Treatment, Control and Prevention}

There is no specific antiviral treatment recommended for COVID-19, and some vaccine is currently available from different country but the effectiveness not yet recognized by concerned body. The treatment is symptomatic, and oxygen therapy represents the major treatment intervention for patients with severe infection. Mechanical ventilation may be necessary in cases of respiratory failure refractory to oxygen therapy, whereas hemodynamic support is essential for 
managing septic shock (30). Different strategies can be used depending on the severity of the patient and local epidemiology $(11 ; 31)$.

A number of investigational agents are being explored for antiviral treatment of COVID-19, and enrolment in clinical trials should be discussed with patients or their proxies. Certain investigational agents have been described in observational studies or are being used anecdotally based on in vitro or extrapolated evidence. It is important to emphasize that there are no controlled data supporting the use of any of these agents, and their efficacy for COVID-19 is unknown (24).

Remdesivir is a novel nucleotide analogue that has activity against SARS-CoV-2 invitro and related corona viruses (including SARS and MERS-CoV) both in vitro and in animal studies. Chloroquine and hydroxychloroquine have antiviral activity in vitro, as well as anti-inflammatory activities. They act on interference with the cellular receptor ACE2, on impairment of acidification of endosomes and on activity against many pro-inflammatory cytokines (e.g., IL-1 and IL6). Other drugs like Tocilizumab, Lopinavir-ritonavir in combination with azithromycin were Corona Virus Disease 2019 (COVID-19) pharmacological experimental options. Support oxygen therapy with high-flow nasal oxygen (HFNO) should be used only in selected patients with hypoxemic respiratory failure (Gennaro et al., 2020 8).

Prevention is, so far, the best practice in order to reduce the impact of COVID-19 considering the lack of effective treatment and it require a collaborative effort from human health and veterinary as well as environmental health to ward one health approach.

\section{Corona Virus in Animals}

The molecular mechanisms of replication as well as the pathogenesis of several corona viruses have been actively studied since the 1970s. Some of the animal viruses, such as porcine transmissible gastroenteritis virus (TGEV), bovine coronavirus (BCoV) and avian infectious bronchitis viruses (IBV), are of veterinary importance. The murine corona virus mouse hepatitis virus (MHV) is studied as a model for human disease (1).

The development of animal models for SARS is a key to our understanding of SARS pathogenesis. Unfortunately, to date an animal model that reproduces the clinical symptoms and pathology observed in SARS-infected patients has not been reported. Nonhuman primates, domestic cats, ferrets, mice, and Golden Syrian hamsters have been experimentally infected with SARS-CoV. These animals support acute self-limited viral replication in the upper and lower respiratory tracts, although differences in outcomes exist. In contrast, pigs and chickens can be experimentally infected with SARS$\mathrm{CoV}$, but these species do not support efficient SARS-CoV replication (32).

\subsection{SARS-CoV-2 in Animals}

The SARS-CoV-2 is zoonotic it affects humans and some animals (33). It is not a surprise to find that domestic animals living closely with COVID-19 positive human cases are exposed to the virus, either through environmental contamination, or through human-animal interactions. Positive findings by polymerase chain reaction (PCR) in household animals such as dogs and cats from households of COVID-19 patients have been reported. Furthermore, some cat sera collected after the outbreak in Wuhan city, Hubei Province were positive for neutralizing antibodies (34). These findings, albeit preliminary, have raised concerns about the possibility of humans transmitting the virus to domestic animals, and the potential role that domestic animals could play in the spread of the virus between each other. Similar potential reverse zoonotic transmission has been seen in other settings such as tigers in Bronx Zoo (35) and minks in two farms in the Netherlands (36).

The interconnectivity of humans, animals and the environment is important in understanding and tackling any threats to food systems, agricultural production and livelihoods. This is particularly important in rural livestock farming communities where animals play an important role for society and food security providing, income, transport, fuel and clothing as well as food. Embracing this challenge, FAO recommends a One Health approach, where animal, human and environmental health work together to achieve the best results (24). But still there is no report of clinical case of covid -19 in animals was found. 


\section{Impacts of SARSCoV-2}

\subsection{Impact of COVID-19 on the Livestock Supply Chain}

Since it is a global pandemic COVID-19 represents an unprecedented emergency and grave societal threat. Protecting public health is the first priority. However, governments, policy makers and the international community must also recognize and attempt to mitigate the negative impacts (current and potential) of the pandemic and related response efforts on key sectors that contribute to food security, nutrition and livelihoods. The livestock sector is a key contributor to these areas, especially for the world's most vulnerable populations. The effects of COVID-19 on the livestock sector are still largely unquantified and yet to be fully felt. Formal assessments have not yet been possible, but current observations reveal disruptions to livestock value chains (37).

The Food and agriculture organization of United Nations on its policy brief on mitigating the impact of covid-19 on the livestock sector developed by its Animal Production and Health Division which is reported on $23^{\text {rd }}$ April 2020 addressed the different impacts of covid-19 on the livestock sector mainly in the supply chain as follows:

\section{Impacts on Animal production}

\subsection{Reduced access to animal feeds, access to inputs, services and access to markets}

Physical distancing and requirements for additional personal protective equipment are reducing the efficiency of industrial feed enterprises. Movement restrictions and illness are resulting in labour shortages and reduced supply of raw materials or other ingredients. Movement restrictions also disrupt transhumance, which cripples pastoralists' ability to feed their animals (37).

Movement restrictions and disruption of national and international trade routes is curbing farmer access to breeding materials and replacement stocks (e.g. day-old chicks and semen). This can compromise sales for input providers. The disruption of public services (e.g. food safety inspection and animal health extension services), combined with interrupted delivery and use of vaccines and medicines is increasing the likelihood of new epidemics, including those involving animal diseases that cause major livestock losses (e.g. African swine fever in East and Southeast Asia) and outbreaks of diseases transmissible to humans. Import restrictions will have greater impact on areas which depend on imports to sustain production or rely on meat and dairy imports for consumption (e.g. large parts of Africa and Small Island developing states) (37).

Closure of live animal markets in many countries means small-scale producers cannot sell their goods. The disruption of the logistical channel and drop in demand are reducing sales and lowering prices. As a result of limited access to markets and slaughterhouses/processing plants, farmers have to keep their stock longer or dump milk, leaving them with higher production costs or important losses (37).

\section{Impacts on Processing}

\subsection{Reduced processing capacity, Compromised storage and conservation}

Staff reductions due to lockdown measures are constraining meat and dairy processing industries, given their labourintensive nature and also due to transport disruptions and changes in retailing and consumption habits are forcing some collectors and processors to stock up. Constrained informal businesses associated to meat and dairy processing in developing countries (i.e. up to 90 percent of volume). COVID-19 prevention and response disrupts these businesses. This disruption removes an outlet for small-scale producers, who often lack the capacity to sell to formal markets (37).

\section{Impacts on Transport}

\subsection{Constrained national and international transport}

Movement restrictions are compromising transport and trade restrictions impact countries exporting livestock products as well as farmers whose incomes depend on exports which is reducing the supply of livestock and livestock products. For instance, in the Philippines, delays of vehicles transporting raw materials for processing meat threatened to cause a shortage until movement bans were loosened. In China, milk processing and transport were disrupted by tight road traffic controls, leading to milk dumping (37). 


\section{Economic Impact}

Besides its worrying effects on human life, the novel strain of corona virus (COVID-19) has the potential to significantly slowdown the global economy (38). The questions how Covid-19 as a health crisis translate to an economic crisis? And why did the spread of the coronavirus bring the global economy to its knees? Are answered in two methods by which coronavirus stifled economic activities; first, the spread of the virus encouraged social distancing which led to the shutdown of financial markets, corporate offices, businesses and events. Second, the exponential rate at which the virus was spreading, and the heightened uncertainty about how bad the situation could get, led to flight to safety in consumption and investment among consumers, investors and international trade partners (39).

(39) empirically examined the impact of social distancing policies on economic activities and stock market indices and found that the increasing number of lockdown days, monetary policy decisions and international travel restrictions severely affected the level of economic activities and the closing, opening, lowest and highest stock price of major stock market indices.

The ongoing COVID-19outbreak affects the economies through numerous channels, including sharp declines in domestic demand, lower tourism and business travel, trade and production linkages, supply disruptions, and health effects. The magnitude of the economic impact will depend on how the outbreak evolves, which remains highly uncertain. Rather than focusing on a single estimate, it is important to explore a range of scenarios, assess the impact conditional on these scenarios materializing, and to update the scenarios as needed (40).

(41) Suggested the three important Economic impact of COVID-19 could affect the global economy through as:

\subsection{Production has already been substantially affected by the shutdown in global areas}

Some other countries are also beginning to feel a direct impact as their authorities put in place similar measures. The slowdown or lockdown in many countries has effects on exporters to other countries. According to the World Bank even without new outbreaks of the disease, these areas will likely experience slow growth in the first half of 2020 (41).

\subsection{Supply chain and market disruption}

Many manufacturing firms rely on imported intermediate inputs from China and other countries affected by the disease. Many companies also rely on sales in China to meet financial goals. The slowdown in economic activity and transportation restrictions in affected countries will likely have an impact on the production and profitability of specific global companies, particularly in manufacturing and in raw materials used in manufacturing (41).

\subsection{Financial impact on firms and financial markets}

Temporary disruptions of inputs and/or production might stress some firms, particularly those with inadequate liquidity. Traders in financial markets may or may not correctly anticipate or understand which firms might be vulnerable. The resulting rise in risk might reveal that one or more key financial market players have taken investment positions that are unprofitable under current conditions, further weakening trust in financial instruments and markets. A possible event would be a significant financial market disruption as participants become concerned about counterparty risk (41).

\subsection{The Future Implications}

Throughout history, epidemics gave humans many challenges, but yet also brought with it many visible and hidden opportunities. Part of the 'hidden opportunities' is building more 'resilient communities' that would prepare the world to be more alert for food-borne diseases (42).

\section{Conclusion}

This review provides an insight into the COVID-19 a picture of its epidemiology, the virus in animal and human and its impact. There is a rapidly growing body of literature on this topic and hopefully it will help for further review on the topic. Only once this pandemic ends, one will be able to assess the health, social and economic impact of this global disaster as a whole hence those dealt in this review may change and or will be explained different way in the future up on the full understanding of the disease and its control has got its reach. We should be able to learn lessons especially in terms of public and global health for any future similar pandemics with one health approach. 


\section{Compliance with ethical standards}

\section{Acknowledgments}

We would like to extend our thanks to College of Agricultural Science Arba Minch University staff members for all round supports.

\section{Disclosure of conflict of interest}

There is no conflict of interest regarding the publication of this paper

\section{References}

[1] Susan R. Weiss and Sonia Navas-Martin. Coronavirus Pathogenesis and the Emerging Pathogen Severe Acute Respiratory Syndrome Coronavirus. Microbiol. Mol. Biol. Revp. 2005; 635-664.

[2] Drosten C, Günther S, Preiser W, Van Der Werf S, Brodt H-R. Identification of a novel coronavirus in patients with severe acute respiratory syndrome. New England Journal of Medicine. 2003; 348: 1967-1976.

[3] Fouchier RA, Hartwig NG, Bestebroer TM, Niemeyer B, De Jong JC. A previously undescribed coronavirus associated with respiratory disease in humans. Proceedings of the National Academy of Sciences of the United States of America. 2004; 101: 6212-6216.

[4] Woo PC, Lau SK, Chu C-m, Chan K-h, Tsoi H-w, Characterization and complete genome sequence of a novel coronavirus, coronavirus HKU1, from patients with pneumonia. Journal of virology. 2005; 79: 884-895.

[5] Gedle D, Endris M, Tessema B, Eshetie S, Ewunetu T. Middle East Respiratory Syndrome Coronavirus: Current Status and Future Implications. JMed Microb Diagn. 2015; 4: 200.

[6] Yang, X.; Yu, Y.; Xu, J.; Shu, H.; Xia, J.; Liu, H.; Wu, Y.; Zhang, L.; Yu, Z.; Fang, M.; et al. Clinical course and outcomes of critically ill patients with SARS-CoV-2 pneumonia in Wuhan, China: A single-centered, retrospective, observational study. Lancet Respir. Med. 2020, 2600, 1-7.

[7] Boheemen S, De Graaf M, Lauber C, Bestebroer TM, Raj VS. Genomic characterization of a newly discovered coronavirus associated withacute respiratory distress syndrome in humans. MBio. 2012; 3: e00473-00412.

[8] Gennaro F, Di , Pizzol D, Marotta C , Antunes M , Racalbuto V , Veronese N, Smith L. Coronavirus Diseases (COVID19) Curren. Int. J. Environ. Res. Public Health 2020, 17: 2690.

[9] Alexander E. Gorbalenya, Susan C. baker, Ralph S. baric, Raoul J. de Groot, Christian Drosten, Anastasia A. Gulyaeva, bart . Haagmans, Chris lauber, Andrey M. leontovich,benjamin W. Neuman, Dmitry Penzar, Stanley Perlman, leo. M. Poon, Dmitry V. Samborskiy, Igor A. Sidorov, Isabel Sola and John Ziebuhr. (2020): The species severe acute respiratory syndromerelated coronavirus: classifying 2019-nCoV and naming it SARS-CoV-2.Nature microbiology. 2020; 5: 536-544.

[10] Cowley JA, CM Dimmock, KM Spann, PJ Walker. Gill-associated virus of Penaeus monodon prawns: an invertebrate viruswith ORF1a and ORF1b genes related to arteri- and coronaviruses. J. Gen.Virol. 2000; 81: 14731484 .

[11] Chan KW, Wong VT, Tang SCW. COVID-19: An update on the epidemiological, clinical, preventive and therapeutic evidence and guidelines of integrative Chinese Western medicine for the management of 2019novel coronavirus disease. Am. J. Chin. Med. 2020; 13: 1-26.

[12] Arabi YM, Alothman A, Balkhy HH. Treatment of middle east respiratory syndrome with a combination of lopinavir-ritonavir and interferon-beta1b (MIRACLE trial): Study protocol for a randomized controlled trial. 2018; 19(1): 81.

[13] Masters PS. The molecular biology of coronaviruses. Adv. Virus Res. 2006; 66: 193-292.

[14] Perlman S, Netland J. Coronaviruses post-SARS: update on replication and pathogenesis. Nat. Rev. Microbiol. 2009; 7: 439-450.

[15] Zumla A, Hui DS, Perlman S. Middle East respiratory syndrome. Lancet. 2015; 386: 995-1007.

[16] Zaki AM, van Boheemen S., Bestebroer TM, Osterhaus ADME and Fouchier RAM. Isolation of a novel coronavirus from a man with pneumonia in Saudi Arabia. N. Engl. J. Med. 2012; 67: 1814-1820. 
[17] Dougan T,J. and Quake S,R. Viral taxonomy derived from evolutionary genome relationships. PLoS ONE (2019);14(8): e0220440. https://doi.org/10.1371/journal.pone.0220440

[18] Resta S, JP Luby, CR Rosenfiled, JD Siegel. Isolation and propagation of a human enteric coronavirus. Science. 1985; 229: 978-981.

[19] Wang Zhou. The coronavirus prevention manual. Skyhorse Publishing, New York. 2020.

[20] WHO. Novel Coronavirus (2019-nCoV), Situation Report 1. 2020.

[21] Hsu LY, Chia PY, Lim JF. The Novel coronavirus (SARS-CoV-2) epidemic. Ann. Acad. Med. Singap. 2020; 49 : 1-3.

[22] Yang X, Yu Y, Xu J, Shu H, Xia J, Liu H, Wu Y, Zhang L, Yu Z, Fang M, Yu T, Wang Y, Pan S, Zou X, Yuan S, Shang Y. Clinical course and outcomes of critically ill patients with SARS-CoV-2 pneumonia in Wuhan, China: a singlecentered, retrospective, observational study. Lancet Respir Med.S2213-2600(20)30079-5. 2020.

[23] Zhou F, Yu T, Du R, Fan G, Liu Y, Liu Z, Xiang J, Wang Y, Song B, Gu X, Guan L, Wei Y, Li H,Wu X, Xu J, Tu S, Zhang Y, Chen H, Cao B. Clinical course and risk factors for mortality ofadult inpatients with COVID-19 in Wuhan, China: a retrospective cohort study. Lancet. 2020; 395(10229): 1054-1062.

[24] FAO. Guidelines to mitigate the impact of the COVID-19 pandemic on livestock production and animal health. Rome.2020.

[25] Lippi G, Simundic AM, Plebani M. Potential preanalytical and analytical vulnerabilities in the laboratory diagnosis of coronavirus disease 2019 (COVID-19). Clin. Chem. Lab. Med. 2020.

[26] Lagier JC, Colson P, Tissot Dupont H, Salomon J, Doudier B, Aubry C, Gouriet F, Baron S, Dudouet P, Flores R. Testing the repatriated for SARS-Cov2: Should laboratory-based quarantine replace traditional quarantine? Travel Med. Infect. Dis. 2020.

[27] Ai T, Yang Z, Hou H, Zhan C, Chen C, Lv W, Tao Q, Sun Z, Xia L. Correlation of chest CT and RT-PCR testing in coronavirus disease (COVID-19) in China: A report of 1014 cases. Radiology. 2019.

[28] Bai HX, Hsieh B, Xion Z, Halsey K, Choi JW, Tran TML, Pan I, Shi LB, Wang DC, Mei J. Performance of radiologists in differentiating COVID-19 from viral pneumonia on chest CT. Radiology. 2020.

[29] Li Y, Xia L. Coronavirus disease 2019 (COVID-19): Role of chest CT in diagnosis and management. AJR Am. J. Roentgenol. 2020; 1-7.

[30] Wang H, Wang S, Yu K. COVID-19 infection epidemic: The medical management strategies in HeilongjiangProvince, China. Crit. Care. 2020; 24: 107.

[31] Chinese Association of Rehabilitation Medicine. Respiratory rehabilitation committee of Chinese Associationof Rehabilitation Medicine. Cardiopulmonary rehabilitation group of Chinese society of physicai medicineand rehabilitation. Zhonghua Jie He He Hu Xi Za Zhi, 43, E029. 2012.

[32] Czub MH, Weingartl S, Czub R, He J. Cao. Evaluation ofmodified vaccinia virus Ankara based recombinant SARS vaccine in ferrets. Vaccine. 2005; 23: 2273-2279.

[33] O'Connor AM, Totton SC, Sargeant JM. A rapid review of evidence of infection of pets andlivestock with human associated coronavirus diseases, SARS, MERS, and COVID-19, and evidence of thefomite potential of pets and livestock. In: Systematic Reviews for Animals and Food (SYREAF). 2020.

[34] Zhang Q, Zhang H, Huang K, Yang Y, Hui X, Gao J, He X, Li C, Gong W, Zhang Y, Peng C, Gao X, Chen H, Zou Z, Shi Z, Jin M. SARS-CoV-2 neutralizing serum antibodies in cats: a serological investigation. BioRxiv. 2020.

[35] OIE. Statement on COVID-19 and mink. 2020.

[36] De Rijksoverheid. Voor Nederland. COVID-19 geconstateerd op twee nertsenbedrijven. In: Nieuwsbericht. 26 April 2020.

[37] FAO. Mitigating the impacts of COVID-19 on the livestock sector, policy brief developed by FAO's Animal Production and Health Division. 2020.

[38] UNCATD. The Global trade impact of the corona virus (covid 19) epidemic, United Nations conference on trade and development, A trade and development report. March 2020.

[39] Ozili P, Arun T. Spillover of COVID-19: impact on the Global Economy. Article in SSRN Electronic Journal. 2020. 
[40] Abdul A, Mia A, Suzette D, Benno F, Ilan N, Patrick O, Jesson P, Donghyun P, Reizle Platitas. The Economic Impact of the COVID-19 Outbreak on Developing Asia. ADB BRIEFS NO.128. 2020.

[41] Mishra, Mukesh Kumar. The World after COVID-19 and its impact on Global Economy, ZBW - Leibniz Information Centre for Economics, Kiel, Hamburg. 2020.

[42] M Buheji, D Ahmed. Foresight of Coronavirus (COVID-19) Opportunities for a Better World American Journal of Economics. 2020; 10(2): 97-108. 